\title{
Technical note: Evaluation of interval between measurements and calculation method for the quantification of enteric methane emissions measured by respiration chamber
}

\author{
Rong Wang, ${ }^{1,2}$ Min Wang, ${ }^{1 *}$ Xiu Min Zhang, ${ }^{1}$ Hua Ming Yang, ${ }^{3}$ Jiang Nan Wen, ${ }^{1,2}$ Zhi Yuan Ma, ${ }^{1}$ Bai Lin Feng, ${ }^{4}$ \\ Jin Ping Deng, ${ }^{2,5}$ and Zhi Liang Tan ${ }^{1}$ \\ ${ }^{1}$ CAS Key Laboratory for Agro-Ecological Processes in Subtropical Region, National Engineering Laboratory for Pollution Control \\ and Waste Utilization in Livestock and Poultry Production, South Central Experimental Station of Animal Nutrition and Feed Science \\ in the Ministry of Agriculture, Institute of Subtropical Agriculture, The Chinese Academy of Sciences, Changsha, Hunan 410125, China \\ ${ }^{2}$ College of Animal Science and Technology, Hunan Agricultural University, Changsha 410128, China \\ ${ }^{3}$ Jilin Academy of Agricultural Sciences, Changchun 130033, China \\ ${ }^{4}$ Youzhuo Animal Husbandry Co. Ltd., Ningxiang, Hunan 410601, China \\ ${ }^{5}$ Guangdong Provincial Key Laboratory of Animal Nutrition Control, Subtropical Institute of Animal Nutrition and Feed, College of Animal Science, \\ South China Agricultural University, Guangzhou, Guangzhou 510642, China
}

\section{ABSTRACT}

Respiration chambers share one analyzer working in parallel, and methane $\left(\mathrm{CH}_{4}\right)$ concentrations have to be measured at certain intervals. The maximum and minimum values in the kinetics of $\mathrm{CH}_{4}$ emissions can be missed during the interval between measurements, which may influence the quantification of $\mathrm{CH}_{4}$ emissions. Chambers must be opened for morning feeding and cleaning, which causes a loss of $\mathrm{CH}_{4}$ data. Calculation methods are needed to estimate the lost $\mathrm{CH}_{4}$ emission data, which may influence the estimated amount of daily $\mathrm{CH}_{4}$ emissions. In this study, we measured the $\mathrm{CH}_{4}$ emissions of 10 growing Chinese Holstein dairy heifers in respiration chambers. Methane concentrations were measured every $0.5 \mathrm{~min}$ to obtain the 23 -h kinetics of $\mathrm{CH}_{4}$ emissions, which were further selected at different intervals between measurements (i.e., 5, 30, $60,120,180$, and $240 \mathrm{~min}$ ) to evaluate the effects of interval on quantification of $\mathrm{CH}_{4}$ emissions. The missing 1-h kinetics of $\mathrm{CH}_{4}$ emissions before feeding were not measured, and 2 calculation methods were used to estimate the missing 1-h kinetics of $\mathrm{CH}_{4}$ emissions: mean value of measuring period (the mean method) and the nearest value of measurement just before chamber opening (the nearest method). The results showed that the rates of $\mathrm{CH}_{4}$ emission from 10 heifers varied from 4.56 to $11.42 \mathrm{~g} / \mathrm{h}$. The increment of intervals decreased maximum rate of $\mathrm{CH}_{4}$ emission and increased minimum rate of $\mathrm{CH}_{4}$ emission. Interval caused less than $5 \%$ of

Received January 3, 2019.

Accepted March 13, 2019.

*Corresponding author: mwang@isa.ac.cn the difference in measuring $\mathrm{CH}_{4}$ emissions. Although the mean method had greater estimated daily $\mathrm{CH}_{4}$ emission than the nearest method, the difference was within $3 \%$. The interval between measurements $(\leq 3 \mathrm{~h})$ and calculation method had little influence on enteric $\mathrm{CH}_{4}$ emission measurements.

Key words: methane emission, respiratory chamber, interval, calculation method

\section{Technical Note}

Enteric methane $\left(\mathrm{CH}_{4}\right)$ is a loss of energy for ruminants and has become a major environmental concern due to its contribution to global warming (Johnson and Johnson, 1995; Reisinger and Clark, 2017; Hristov et al., 2018). Respiration chambers are frequently used for measuring enteric $\mathrm{CH}_{4}$ emissions in ruminants (Storm et al., 2012; Hammond et al., 2016). The respiration chamber system generally consists of several chambers (Derno et al., 2009) that share one analyzer working in parallel; as a result, it measures gas concentrations at certain intervals (Wang et al., 2017). Therefore, $\mathrm{CH}_{4}$ emissions are measured at several time points throughout the day. Rate of $\mathrm{CH}_{4}$ emission is not constant throughout the day (Wang et al., 2015, 2016). Measuring $\mathrm{CH}_{4}$ concentrations at different intervals can miss maximum and minimum values and thus affect the estimate of total $\mathrm{CH}_{4}$ emissions, which need verification.

Chambers need to be cleaned and gas analyzers need to be calibrated every day during the period of $\mathrm{CH}_{4}$ measurement (Derno et al., 2009). Based on our experience, it takes about $1 \mathrm{~h}$ to clean the chambers before morning feeding; therefore, 24-h $\mathrm{CH}_{4}$ emissions are estimated using 23-h $\mathrm{CH}_{4}$ emission data. Two calculation methods can be used to estimate the missing 1-h 
$\mathrm{CH}_{4}$ emission data: the mean value of the 23-h measuring period (referred to as the mean method), and the nearest value $(23 \mathrm{~h})$ of measurement just before chamber opening (referred to as the nearest method). The rate of $\mathrm{CH}_{4}$ emission tends to be at the lowest level before morning feeding and then increases after feeding. Therefore, the mean values are higher after feeding than before feeding, leading to the overestimation of daily $\mathrm{CH}_{4}$ emissions. Hristov et al. (2018) reported that the mean method can cause a small overestimation of daily $\mathrm{CH}_{4}$ emissions. Further studies are still needed to evaluate the effect of calculation method on estimate of daily $\mathrm{CH}_{4}$ emissions.

All experimental procedures followed institutional guidelines for the care and use of animals and were approved by the Animal Care Committee, Institute of Subtropical Agriculture, the Chinese Academy of Sciences, Changsha, China. The experiment was conducted at Youzhuo Animal Husbandry Co. Ltd. in the NingXiang County of Hunan Province, China. Ten growing Chinese Holstein dairy heifers with a wide range of BW (Table 1) were selected for this experiment. Cows were fed a TMR consisting of $50 \%$ corn silage, $25 \%$ corn grain, $10 \%$ soybean meal, $7.5 \%$ cottonseed meal, $5 \%$ dried distillers grains with solubles, $0.1 \%$ montmorillonite, and $4.9 \%$ premix (DM basis). The premix was formulated to provide $1,000,000$ IU of vitamin A, 200,000 IU of vitamin D, 1,250 IU of vitamin E, 8,000 $\mathrm{mg}$ of $\mathrm{Zn}, 80 \mathrm{mg}$ of Se, $120 \mathrm{mg}$ of I, 2,000 $\mathrm{mg}$ of Fe, 40 $\mathrm{mg}$ of $\mathrm{Co}, 2,500 \mathrm{mg}$ of $\mathrm{Mn}$, and 2,000 $\mathrm{mg}$ of $\mathrm{Cu}$ (per kilogram of premix). The DM of the TMR was $477 \mathrm{~g} /$ $\mathrm{kg}$, and the chemical composition of the TMR was 139 $\mathrm{g}$ of CP, $472 \mathrm{~g}$ of NDF, $235 \mathrm{~g}$ of ADF, and $232 \mathrm{~g}$ of starch $/ \mathrm{kg}$ of TMR (DM basis). Gross energy in TMR was $15.2 \mathrm{MJ} / \mathrm{kg}$ of TMR. Cows were fed twice daily at 0900 and $1600 \mathrm{~h}$ and had free access to feeds and fresh water.
Enteric $\mathrm{CH}_{4}$ emissions were measured and calculated according to the protocol of Wang et al. (2015). Briefly, $\mathrm{CH}_{4}$ concentrations were measured (every 0.5 min) continuously for $23 \mathrm{~h}$ after morning feeding in inlet and outlet gas using an FGD F200 sensor (Axetris AG, Kaegiswil, Switzerland). The $\mathrm{CH}_{4}$ concentration in the remaining $1 \mathrm{~h}$ before morning feeding, for chamber cleaning and feeding, was not measured. It took less than 3 min to provide fresh feed during the afternoon feeding, and $\mathrm{CH}_{4}$ concentrations were continuously measured in this study.

Methane concentrations were further selected at different intervals (i.e., 5, 30, 60, 120, 180, and 240 min) using measured 23-h kinetics of $\mathrm{CH}_{4}$ emissions. The 23- $\mathrm{CH}_{4}$ emissions of different intervals were then recalculated using equations provided by Wang et al. (2015):

$$
\begin{gathered}
\Delta V_{i}=\left[\begin{array}{c}
R_{g} \times\left(\frac{C C_{i}+C C_{i-1}}{2}-\frac{C A_{i}+C A_{i-1}}{2}\right) \\
+V_{c} \times 1,000 \times\left(C C_{i}+C C_{i-1}\right)
\end{array}\right] / 10^{6} \\
R_{i}=\frac{\Delta V_{i}}{t_{i}-t_{i-1}} \\
V_{h}=\sum_{i=1}^{i=n} \Delta V_{i},
\end{gathered}
$$

where $\Delta V_{i}$ is the amount of $\mathrm{CH}_{4}$ emission (L) between time $t_{i}$ and $t_{i-1} ; R_{q}$ is the flow rate of gas $(\mathrm{L} / \mathrm{h})$ in the duct; $C C_{i}$ is the concentration of $\mathrm{CH}_{4}\left(10^{6} \mathrm{~L} / \mathrm{L}\right)$ in the outlet air at time $t_{i} ; C A_{i}$ is the concentration of $\mathrm{CH}_{4}$ $\left(10^{6} \mathrm{~L} / \mathrm{L}\right)$ in the inlet air at time $t_{i} ; V_{C}$ is the volume of the chamber $\left(\mathrm{m}^{3}\right) ; R_{i}$ is the rate of $\mathrm{CH}_{4}$ emission $(\mathrm{L} / \mathrm{h})$

\begin{tabular}{|c|c|c|c|c|c|c|}
\hline \multirow[b]{2}{*}{ Cow } & \multirow{2}{*}{$\begin{array}{l}\text { BW } \\
(\mathrm{kg})\end{array}$} & \multirow{2}{*}{$\begin{array}{l}\text { Age } \\
(\mathrm{mo})\end{array}$} & \multirow{2}{*}{$\begin{array}{c}\mathrm{CH}_{4} \text { emission } \\
(\mathrm{g} / 23 \mathrm{~h})\end{array}$} & \multicolumn{3}{|c|}{$\mathrm{CH}_{4}$ emission rate $(\mathrm{g} / \mathrm{h})$} \\
\hline & & & & Mean & Maximum & Minimum \\
\hline 1 & 279 & 6.9 & 105 & 4.6 & 7.6 & 2.3 \\
\hline 2 & 330 & 9.5 & 194 & 8.4 & 12.6 & 5.4 \\
\hline 3 & 340 & 10.7 & 181 & 7.9 & 11.1 & 4.2 \\
\hline 4 & 352 & 9.7 & 172 & 7.5 & 11.1 & 4.7 \\
\hline 5 & 368 & 11.8 & 200 & 8.7 & 12.5 & 5.6 \\
\hline 6 & 385 & 8.9 & 153 & 6.6 & 10.4 & 3.9 \\
\hline 7 & 402 & 11.8 & 194 & 8.4 & 13.6 & 5.0 \\
\hline 8 & 419 & 11.9 & 263 & 11.4 & 17.6 & 7.0 \\
\hline 9 & 419 & 11.9 & 210 & 9.1 & 13.8 & 5.8 \\
\hline 10 & 427 & 11.5 & 187 & 8.1 & 11.8 & 5.1 \\
\hline Mean & 372 & 10.5 & 186 & 8.1 & 12.2 & 4.9 \\
\hline SEM & 15.0 & 0.53 & 12.8 & 0.56 & 0.81 & 0.40 \\
\hline
\end{tabular}
between $t_{i}$ and $t_{i-1} ; i$ is the number of sampling within

Table 1. Characteristics of the dairy heifers used $(\mathrm{n}=10)$ 

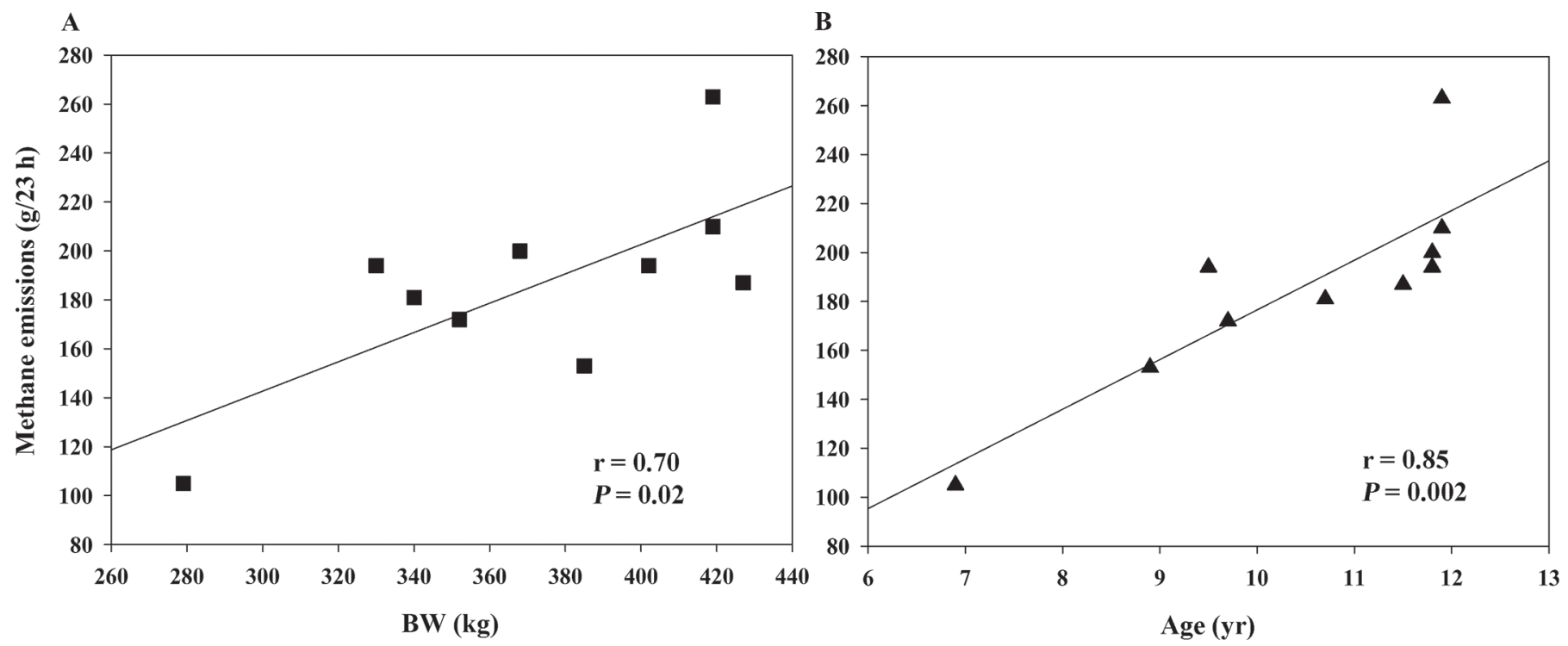

Figure 1. Relationships of 23-h methane emissions with BW (A) and age (B) in dairy heifers ( $\mathrm{n}=10)$. The lines in each panel are the best linear regression line. Each point represents the data of $1 \mathrm{cow}$, with a total of 10 data points.

$23 \mathrm{~h} ; n$ is the total number of samplings; and $V_{h}$ is the amount of $\mathrm{CH}_{4}$ emission (L) within $23 \mathrm{~h}$.

Daily (24-h) $\mathrm{CH}_{4}$ emissions can be calculated by summing measured 23-h $\mathrm{CH}_{4}$ emissions and 1-h missing $\mathrm{CH}_{4}$ emissions. The 1-h missing $\mathrm{CH}_{4}$ emissions were estimated using the mean and nearest methods. Mean method used the mean rate of measured $23-\mathrm{h} \mathrm{CH}_{4}$ emission, whereas the nearest method used the nearest value (23-h) of measurement just before chamber opening.

Statistical analysis was performed using SPSS 21.0 software (SPSS Inc., Chicago, IL). Effects of interval were analyzed by mixed linear procedure, and the analytic model included interval $(i=7 ; 0.5,5,30,60,120$, 180 , and $240 \mathrm{~min})$ as fixed effect and dairy heifer $(j$ $=10: 1,2,3,4,5,6,7,8,9$, and 10) as the random effect and repeated measures, with covariance being compound symmetry structure. Effect of calculation method was analyzed using mixed linear procedure, and the analytic model included calculation method ( $i$ $=2$, mean and nearest methods) as the fixed effects and dairy heifer $(j=10,1,2,3,4,5,6,7,8,9$, and 10) as the random effect and repeated measures, with covariance being compound symmetry structure. Association between measured 23-h $\mathrm{CH}_{4}$ emissions and BW or age was evaluated using linear regression model. Statistical significance was declared at $P \leq 0.05$, and a tendency toward significance was declared at $0.05<$ $P \leq 0.10$.

The 23-h kinetics of $\mathrm{CH}_{4}$ emissions and rates of $\mathrm{CH}_{4}$ emission varied widely among 10 cows (Table 1), and the amount of $23-\mathrm{h} \mathrm{CH}_{4}$ emissions was positively cor- related with $\mathrm{BW}(\mathrm{r}=0.70 ; P=0.02)$ and age $(\mathrm{r}=$ $0.85 ; P=0.002$ ) of cows (Figure 1). Animal BW, a key explanatory variable for $\mathrm{CH}_{4}$ emissions, is always included in the model to predict $\mathrm{CH}_{4}$ emission (Moraes et al., 2014). Some cows with similar BW can have different $\mathrm{CH}_{4}$ emissions due to having different genetic backgrounds (Jonker et al., 2016).

The rates of $\mathrm{CH}_{4}$ emission were not constant throughout the day and ranged between 4.6 and 11.4 $\mathrm{g} / \mathrm{h}$ (Figure 2). The maximum rate of $\mathrm{CH}_{4}$ emission occurred about 1 to $2 \mathrm{~h}$ after feeding, and then the rate of $\mathrm{CH}_{4}$ emission gradually declined to the basal level. When animals were fed twice per day, 2 distinct peaks were observed in the diurnal kinetics of $\mathrm{CH}_{4}$ emissions (Figure 2). This phenomenon is also reported by previous studies (van Zijderveld et al., 2010; Guyader et al., 2015; Wang et al., 2018). However, when measurement frequency was decreased by increasing the interval between measurements, diurnal kinetics of $\mathrm{CH}_{4}$ emissions changed significantly $(P<0.001$; Table 2$)$. For example, when the interval was increased from 0.5 to 240 min, apparent diurnal kinetics of $\mathrm{CH}_{4}$ emissions changed so that instead of 2 peaks, only 1 peak was detected. Furthermore, increased interval significantly $(P \leq 0.05)$ decreased maximum rate of $\mathrm{CH}_{4}$ emission and increased minimum rate of $\mathrm{CH}_{4}$ emission (Table 2). Our result confirmed that increasing interval between measurements could result in not detecting the actual or true maxima and minima for rates of $\mathrm{CH}_{4}$ emission.

When the interval was increased from 0.5 to $180 \mathrm{~min}$, the calculated amount of $23-\mathrm{h} \mathrm{CH}_{4}$ emissions was not 
affected. Although the maximum and minimum values in the kinetics of $\mathrm{CH}_{4}$ emissions were missed when $\mathrm{CH}_{4}$ concentrations were measured at different intervals, the missed maximum and minimum values might offset each other, leading to the unchanged estimate of total $\mathrm{CH}_{4}$ emissions. When the interval was extended to 4 $\mathrm{h}$, the calculated amount of $23-\mathrm{h} \mathrm{CH}_{4}$ emissions was significantly $(P<0.001)$ increased compared with the estimate made using measurements at 0.5 -min intervals. Similar results have been observed using the GreenFeed system. For example, Manafiazar et al. (2017) found that increased intervals between measurements caused an increase in estimate of $\mathrm{CH}_{4}$ emissions in beef cattle, and these results can be inconsistent if only a small number of samples are measured. However, in the current research, the extent of increased maximum
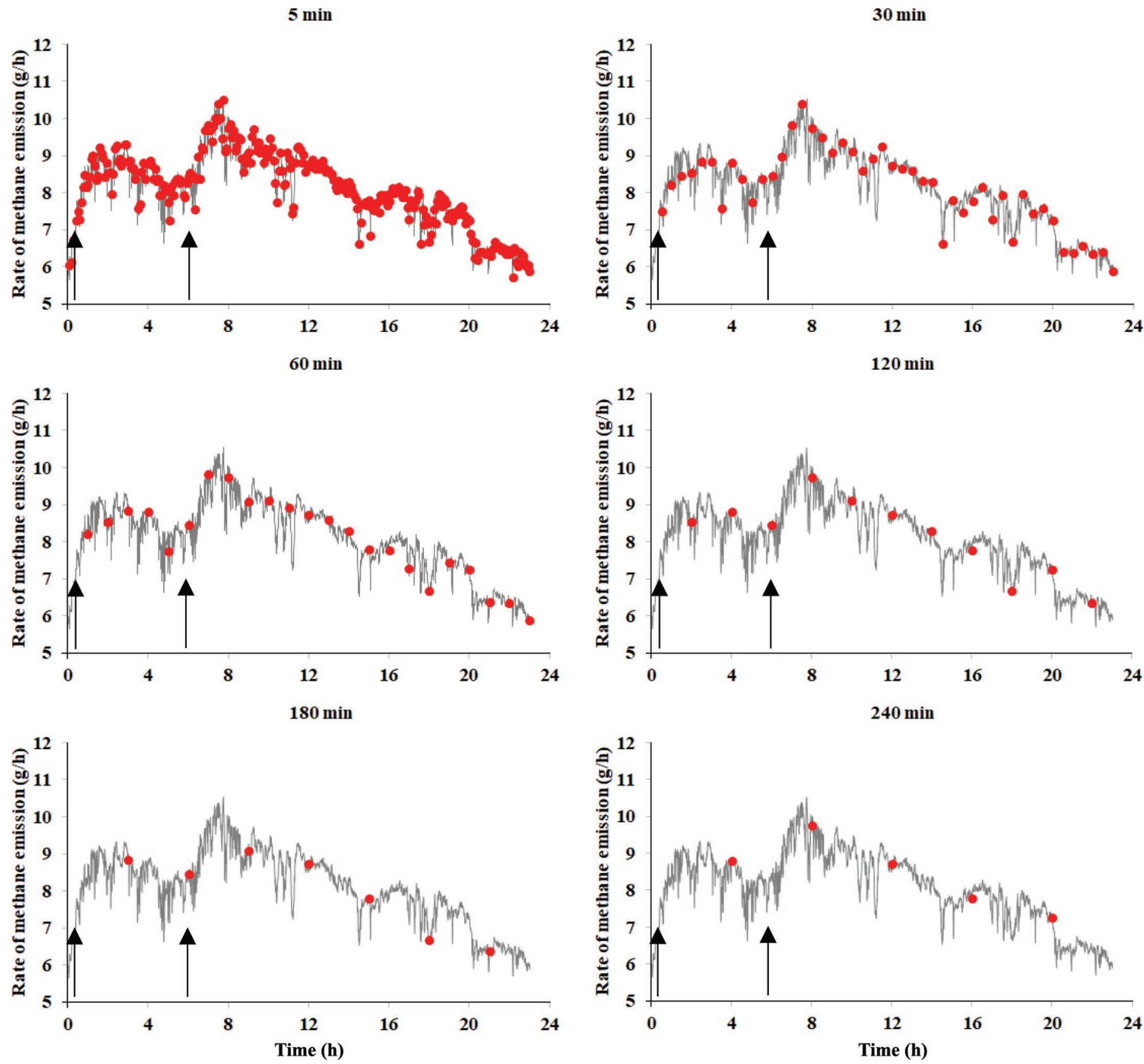

Figure 2. The kinetics of 23-h rate of methane emission $(\mathrm{g} / \mathrm{h})$ from dairy heifers at different intervals (mean value of 10 animals). Black points are the methane data measured every $0.5 \mathrm{~min}$, and red points are the selected methane data at different intervals between measurements (i.e., 10, 30, 60, 120, 180, and $240 \mathrm{~min}$ ). Arrows show the time when the fresh feeds were provided. 
Table 2. Effect of interval between measurements on enteric $\mathrm{CH}_{4}$ emissions in dairy heifers $(\mathrm{n}=10)$

\begin{tabular}{lcccc}
\hline & & \multicolumn{3}{c}{$\mathrm{CH}_{4}$ emission rate $(\mathrm{g} / \mathrm{h})$} \\
\cline { 3 - 5 } Interval $(\mathrm{CHin})$ & $\begin{array}{c}\mathrm{CH}_{4} \text { emission } \\
(\mathrm{g} / 23 \mathrm{~h})\end{array}$ & Mean & Maximum & Minimum \\
\hline 0.5 & $186^{\mathrm{a}}$ & $8.1^{\mathrm{a}}$ & $12.2^{\mathrm{d}}$ & $4.9^{\mathrm{a}}$ \\
5 & $186^{\mathrm{a}}$ & $8.1^{\mathrm{a}}$ & $11.8^{\mathrm{cd}}$ & $5.2^{\mathrm{ab}}$ \\
30 & $186^{\mathrm{a}}$ & $8.1^{\mathrm{a}}$ & $11.4^{\mathrm{c}}$ & $5.6^{\mathrm{bc}}$ \\
60 & $186^{\mathrm{a}}$ & $8.1^{\mathrm{a}}$ & $10.8^{\mathrm{b}}$ & $5.7^{\mathrm{cd}}$ \\
120 & $188^{\mathrm{a}}$ & $8.2^{\mathrm{a}}$ & $10.1^{\mathrm{a}}$ & $6.0^{\mathrm{de}}$ \\
240 & $184^{\mathrm{a}}$ & $8.0^{\mathrm{a}}$ & $9.8^{\mathrm{a}}$ & $7.0^{\mathrm{f}}$ \\
SEM & $194^{\mathrm{b}}$ & $8.5^{\mathrm{b}}$ & $10.1^{\mathrm{a}}$ & 0.18 \\
$P$-value & & & & \\
Interval & 1.9 & 0.08 & 0.26 & $<0.001$ \\
Animal & $<0.001$ & $<0.001$ & $<0.001$ & $<0.001$ \\
\hline
\end{tabular}

${ }^{\mathrm{a}-\mathrm{f}}$ Means within a column with different superscripts differ $(P \leq 0.05)$.

value was about $+4.6 \%$, which was smaller than $21.9 \%$ obtained using the GreenFeed system (Jonker et al., 2016). We surmise that different measurement systems and intervals between measurements may be the cause of this variation.

The calculated amount of daily $24-\mathrm{h} \mathrm{CH}_{4}$ emissions was further investigated using the mean method and the nearest method to estimate 1-h missing $\mathrm{CH}_{4}$ emissions (Table 3). Compared with the nearest method, the mean method resulted in a greater estimate of daily $\mathrm{CH}_{4}$ emissions $(P<0.001)$ in dairy heifers (Table 3 ). This result was within our expectations. The rate of $\mathrm{CH}_{4}$ emission was always lowest before morning feeding because of unavailable or residual feeds for animals. However, calculation method seemed to have little effect on calculating daily $\mathrm{CH}_{4}$ emissions, as daily $\mathrm{CH}_{4}$ emissions were just 0.74 to $2.53 \%$ greater when estimated using the mean method than when estimated using the nearest method. This finding is consistent with the findings reported by Hristov et al. (2018), who also estimated that the mean method may overestimate daily $\mathrm{CH}_{4}$ emissions by approximately $2 \%$.

Increasing the interval between measurements may lead to an underestimation of maxima and an overestimation of minima with respect to the pattern of daily enteric $\mathrm{CH}_{4}$ emissions but does not affect the estimate of 23- $\mathrm{h} \mathrm{CH}_{4}$ emission if the interval between measurements is $\leq 3 \mathrm{~h}$. The mean method has greater estimated daily $\mathrm{CH}_{4}$ emission than the nearest method, but the difference is within $3 \%$.

\section{ACKNOWLEDGMENTS}

This work was supported by National Key Research and Development Program of China (grant no. 2018YFD0501800 and 2016YFD0500504), National Natural Science Foundation of China (grant no. 31561143009), Hunan Province Science and Technology Plan (grant no. 2017NK1020), China Agriculture Research System (grant no. CARS-36), and Youth

Table 3. Effect of calculation method on daily methane emission $(\mathrm{g} / 24 \mathrm{~h})$ in dairy heifers $(\mathrm{n}=10)$

\begin{tabular}{|c|c|c|c|c|c|}
\hline \multirow[b]{2}{*}{ Interval (min) } & \multicolumn{2}{|c|}{ Calculation method ${ }^{1}$} & \multirow{2}{*}{$\begin{array}{c}\text { Difference } \\
(\%)\end{array}$} & \multirow[b]{2}{*}{ SEM } & \multirow[b]{2}{*}{$P$-value } \\
\hline & Mean & Nearest & & & \\
\hline 0.5 & 200 & 198 & 1.1 & $<0.001$ & $<0.001$ \\
\hline 5 & 199 & 197 & 1.0 & $<0.001$ & $<0.001$ \\
\hline 30 & 201 & 199 & 0.9 & $<0.001$ & $<0.001$ \\
\hline 60 & 195 & 193 & 1.1 & $<0.001$ & $<0.001$ \\
\hline 120 & 203 & 198 & 2.3 & $<0.001$ & $<0.001$ \\
\hline 180 & 200 & 194 & 2.7 & $<0.001$ & $<0.001$ \\
\hline 240 & 203 & 197 & 2.7 & $<0.001$ & $<0.001$ \\
\hline
\end{tabular}

${ }^{1}$ Mean method $=$ the missing 1 -h data are replaced by the mean value of the 23 -h measuring period. Nearest method $=$ the missing 1 -h data are the nearest value of measurement just before chamber opening (i.e., emission data at $23 \mathrm{~h}$ ). 
Innovation Promotion Association CAS (grant no. 2016327). The authors declare that they have no conflict of interest.

\section{REFERENCES}

Derno, M., H. G. Elsner, E. A. Paetow, H. Scholze, and M. Schweigel. 2009. Technical note: A new facility for continuous respiration measurements in lactating cows. J. Dairy Sci. 92:2804-2808. https: //doi.org/10.3168/jds.2008-1839.

Guyader, J., M. Eugene, B. Meunier, M. Doreau, D. P. Morgavi, M. Silberberg, Y. Rochette, C. Gerard, C. Loncke, and C. Martin. 2015. Additive methane-mitigating effect between linseed oil and nitrate fed to cattle. J. Anim. Sci. 93:3564-3577. https://doi.org/ 10.2527/jas.2014-8196.

Hammond, K. J., L. A. Crompton, A. Bannink, J. Dijkstra, D. R. Yáñez-Ruiz, P. O'Kiely, E. Kebreab, M. A. Eugène, Z. Yu, K. J. Shingfield, A. Schwarm, A. N. Hristov, and C. K. Reynolds. 2016. Review of current in vivo measurement techniques for quantifying enteric methane emission from ruminants. Anim. Feed Sci. Technol. 219:13-30. https://doi.org/10.1016/j.anifeedsci.2016.05.018.

Hristov, A. N., E. Kebreab, M. Niu, J. Oh, A. Bannink, A. R. Bayat, T. M. Boland, A. F. Brito, D. P. Casper, L. A. Crompton, J. Dijkstra, M. Eugène, P. C. Garnsworthy, N. Haque, A. L. F. Hellwing, P. Huhtanen, M. Kreuzer, B. Kuhla, P. Lund, J. Madsen, C. Martin, P. J. Moate, S. Muetzel, C. Muñoz, N. Peiren, J. M. Powell, C. K. Reynolds, A. Schwarm, K. J. Shingfield, T. M. Storlien, M. R. Weisbjerg, D. R. Yáñez-Ruiz, and Z. Yu. 2018. Symposium review: Uncertainties in enteric methane inventories, measurement techniques, and prediction models. J. Dairy Sci. 101:6655-6674. https://doi.org/10.3168/jds.2017-13536.

Johnson, K. A., and D. E. Johnson. 1995. Methane emissions from cattle. J. Anim. Sci. 73:2483-2492. https://doi.org/10.2527/1995 $.7382483 \mathrm{x}$.

Jonker, A., G. Molano, C. Antwi, and G. C. Waghorn. 2016. Enteric methane and carbon dioxide emissions measured using respiration chambers, the sulfur hexafluoride tracer technique, and a GreenFeed head-chamber system from beef heifers fed alfalfa silage at three allowances and four feeding frequencies. J. Anim. Sci. 94:4326-4337. https://doi.org/10.2527/jas.2016-0646.
Manafiazar, G., S. Zimmerman, and J. A. Basarab. 2017. Repeatability and variability of short-term spot measurement of methane and carbon dioxide emissions from beef cattle using GreenFeed emissions monitoring system. Can. J. Anim. Sci. 97:118-126. https:// doi.org/10.1139/cjas-2015-0190.

Moraes, L. E., A. B. Strathe, J. G. Fadel, D. P. Casper, and E. Kebreab. 2014. Prediction of enteric methane emissions from cattle. Glob. Chang. Biol. 20:2140-2148. https://doi.org/10.1111/gcb 12471.

Reisinger, A., and H. Clark. 2017. How much do direct livestock emissions actually contribute to global warming? Glob. Chang. Biol. 24:1-13. https://doi.org/10.1111/gcb.13975.

Storm, I. M. L. D., A. L. F. Hellwing, N. I. Nielsen, and J. Madsen. 2012. Methods for measuring and estimating methane emission from ruminants. Animals (Basel) 2:160-183. https://doi.org/10 $.3390 /$ ani2020160.

van Zijderveld, S. M., W. J. Gerrits, J. A. Apajalahti, J. R. Newbold, J. Dijkstra, R. A. Leng, and H. B. Perdok. 2010. Nitrate and sulfate: Effective alternative hydrogen sinks for mitigation of ruminal methane production in sheep. J. Dairy Sci. 93:5856-5866. https:// doi.org/10.3168/jds.2010-3281.

Wang, M., R. Wang, X. Sun, L. Chen, S. Tang, C. Zhou, X. Han, J. Kang, Z. Tan, and Z. He. 2015. A mathematical model to describe the diurnal pattern of enteric methane emissions from non-lactating dairy cows post-feeding. Anim. Nutr. 1:329-338. https://doi .org/10.1016/j.aninu.2015.11.009.

Wang, M., R. Wang, T. Y. Xie, P. H. Janssen, X. Z. Sun, K. A. Beauchemin, Z. L. Tan, and M. Gao. 2016. Shifts in rumen fermentation and microbiota are associated with dissolved ruminal hydrogen concentrations in lactating dairy cows fed different types of carbohydrates. J. Nutr. 146:1714-1721. https://doi.org/10.3945/ jn.116.232462.

Wang, M., R. Wang, X. Zhang, E. M. Ungerfeld, D. Long, H. Mao, J. Jiao, K. A. Beauchemin, and Z. Tan. 2017. Molecular hydrogen generated by elemental magnesium supplementation alters rumen fermentation and microbiota in goats. Br. J. Nutr. 118:401-410. https://doi.org/10.1017/S0007114517002161.

Wang, R., M. Wang, E. M. Ungerfeld, X. M. Zhang, D. L. Long, H. X. Mao, J. P. Deng, A. Bannink, and Z. L. Tan. 2018. Nitrate improves ammonia incorporation into rumen microbial protein in lactating dairy cows fed a low-protein diet. J. Dairy Sci. 101:97899799. https://doi.org/10.3168/jds.2018-14904. 